\title{
Feature
}

\section{CCS - between a rock and a hard place?}

For the past decade and a half $\mathrm{CO}_{2}$ has been stored underground successfully, and scientists are becoming increasingly confident that carbon capture and storage can work. But many people are still not convinced about its viability and are worried about costs. What needs to be done to reassure the public and the investment community?

To date, more than thirty million tonnes of $\mathrm{CO}_{2}$ have been stored at Sleipner and Snohvit (Norway), Weyburn (Canada) and In Salah (Algeria), with smaller amounts at pilot-scale sites around the world. The industrial-scale storage operations have demonstrated the overall feasibility of CCS in a variety of surface and geological settings and pilot-scale capture projects have provided the key insights necessary for scale-up. The ability to monitor and track the injected $\mathrm{CO}_{2}$ in the subsurface has also been demonstrated (e.g Eiken et al in press) and we are learning more all the time. And yet scepticism around the overall viability of the technology is rife. There are three main planks to the sceptics' arguments: a perceived lack of global storage capacity, storage safety, and, the elephant in the room, cost.

\section{Storage capacity}

Issues of storage capacity have been thrown into focus by recent papers by Ehlig-Economides and Economides (2010). These authors have stated that, because of unavoidable pressure increase in storage reservoirs, large-scale CCS is not viable. The central tenet of the Economides' argument is that, to assure containment, storage must be restricted to 'closed' systems sealed on all sides. With this constraint, injecting $\mathrm{CO}_{2}$, even in relatively small quantities will cause reservoir pressures to rise strongly. In fact the closed system requirement for secure containment is simply incorrect and can be easily dismissed, indeed it elicited some remarkably robust rebuttals which arose independently from a number of research groups around the world, both via internet forums (e.g. ZEP 2010) and also in print (Cavanagh, Haszeldine and Blunt 2010).

The E\&E work does, nevertheless, raise interesting points about the extent to which natural reservoirs might behave as partially closed systems or show evidence of strong flow barriers. A perspective by Zhou and Birkholzer (last issue) investigated some of the issues surrounding very large-scale storage in closed, partially-closed and open reservoir systems. It is clear that pressure-related issues cannot be ignored and it is important not to be too sanguine about them.

Early large-scale storage projects, particularly in aquifers need to be sure that reservoir quality is up to scratch. It is a fact that predictive simulations using uniform 'averaged' properties give more favourable storage outcomes than simulations which incorporate heterogeneity within reservoirs of otherwise equivalent bulk properties. Some simple 'cautionary' indicators regarding reservoir requirements (thickness, permeability, heterogeneity etc) were listed in the CO2STORE Best Practice Manual (Chadwick et al 2008), and experience to date has revealed little to refute these. Sleipner is a good example of reasonably large-scale storage in a reservoir whose storage properties are plainly fit-for-purpose. Ehlig - Economides \& Economides, seemingly misunderstanding the time-lapse seismic results, cited Sleipner as an 
example of a reservoir where pressure buildup was retarding plume migration. Time-lapse geophysical monitoring at Sleipner is second to none (e.g Arts et al. 2008) and recent research by the author indicates that time-lapse seismic changes in the reservoir (or lack thereof) point to quite marginal pressure increases of one bar or less. This is consistent with an uncompartmentalised reservoir where the formation fluids are able to flow freely.

We do need to be aware that not all reservoirs behave as well as the Utsira Sand, and serious consideration needs to be given to evaluating dynamic flow behaviour on a site by site basis. However as Eiken et al (2011) point out, with proper site characterisation, intelligent injection strategies and, where necessary, use of established pressure management techniques, there is no reason why large amounts of $\mathrm{CO}_{2}$ cannot be stored in a wide range of reservoir types.

Recent experience shows that once a story hits the global information network it develops a life of its own. Last year the UK press quoted a debate held in the Scottish Parliament, concerning a draft planning proposal for a new coal-fired power-plant, at Hunterston in the west of Scotland. The Green Party MSP for Glasgow is opposed to the idea and backed his arguments by quoting the Economides' paper as showing that CCS could not work. It is difficult to escape the irony here, as Professor Economides is also, to judge by his internet bloggings, a prominent climate change denier.

\section{Storage security}

It seems that CCS is never far from the headlines these days. Issues concerning site safety are clearly always going to be contentious, but fact and fiction seem to be easily blurred. In late 2009 an article appeared in New Scientist stating that the Sleipner $\mathrm{CO}_{2}$ injection operation had triggered a Magnitude 4 Earthquake in 2008, adding for effect that a larger earthquake than this might even cause a tsunami. The source of these suppositions was a consultant in California, but the basis of his assertions was unclear. So what are the facts? The BGS global seismicity database provides coverage of North Sea seismicity down to about Magnitude 2.5. The data show that no earthquake larger than Magnitude 3 has occurred within $50 \mathrm{~km}$ of Sleipner since injection began in 1996. The best candidate for the rumour was a 2008 event of Magnitude 3.1, some $55 \mathrm{~km}$ from the injection site. In fact seismicity in the Sleipner area is rather low and has actually decreased somewhat since injection began, though there is nothing significant in this natural variation. In terms of tsunamis, the largest historic earthquake in the North Sea occurred in 1931 and had a magnitude of 6.1, over 30000 times bigger than the event in 2008, and with no trace of a tsunami. When presented with these observations New Scientist withdrew the article from their website and a retraction was published. But by then the damage was done, a lot of people doubtless saw the original article but not the retraction. I imagine that some who did just assumed it was a cover up - the establishment closing ranks conspiracy theories are so much more exciting than the truth.

More recently, stories surfaced in the press about supposed $\mathrm{CO}_{2}$ leakage at the Weyburn EOR project in Canada. A farming couple who live in the area claim that leaking $\mathrm{CO}_{2}$ is bubbling into ponds, asphyxiating animals and creating strange algal blooms. A consultant was hired by the couple to measure $\mathrm{CO}_{2}$ levels in the soil and his results were used to substantiate the leakage claims. However, soil gas surveys had also been undertaken ten years earlier as the $\mathrm{CO}_{2}$ injection operation began. The consultant's recent measurements lie wholly within the range of values found on the much earlier surveys and on this basis his claims have been dismissed. A key plank in the rebuttal is the evidence from the earlier baseline surveys. 
The lesson to be learned from these experiences is that the importance of robust background or baseline measurements in demonstrating storage integrity cannot be overstated, particularly with regard to public perception. Sleipner didn't have a dedicated seismicity recording programme, but the existence of a robust, long-term 'third-party' database was sufficient to conclusively crush an inaccurate rumour.

\section{Costs}

There are different views as to whether CCS is cost-competitive with the cheaper end of the spectrum of renewable energy alternatives. Whatever the current costs, comparison with deployment experience of similar large-scale technology suggests that very significant cost reductions are likely. Evidence from the take-up of flue gas desulphurisation in China showed a staggering 90\% decrease in costs between 2000 and 2006 - this due to economies of manufacturing scale and improved design integration. This type of cost reduction could well be realisable for CCS, particularly with the potential for second and third generation capture technologies. It is difficult to envisage similar scope for cost reductions in, for example, wind generation.

The problem that CCS faces is not life-cycle costs, which have the potential to become very competitive compared with the main renewable options, but the fact that, unlike many renewable technologies, CCS facilities cannot be installed piecemeal. Currently, governments can just about afford to subsidise a relatively low level of renewable-generated electricity in their economies, but with CCS there is an unavoidable requirement for large initial capital input. To build a capture plant, install a pipeline transport system and develop a suitable storage site requires serious upfront financing. It also requires a guaranteed income-stream based around a stable, and sufficiently high, carbon price into the foreseeable future. Without these, few are currently prepared to take the risk.

To sum up, CCS is unique among the low-carbon energy tools in preventing $\mathrm{CO}_{2}$ reaching the atmosphere whilst fossil fuel is being actually burnt. No other clean energy option does this. Given that fossil carbon emissions are still increasing, the case for CCS is undeniable. In my view technical and safety issues can be overcome, but the high initial costs remain. To overcome this formidable hurdle requires strong and unified international policy.

\section{References;}

1. Eiken, O., Ringrose, P., Hermanrud, C., Nazarian, B., Torp, T. \& Høier, L. Lessons learned from 14 years of CCS operations: Sleipner, In Salah and Snøhvit. Energy Procedia (in press). [2011].

2. Arts, R.J., Chadwick, R.A., Eiken, O., Thibeau, S. and Nooner, S. Ten years' experience of monitoring $\mathrm{CO}_{2}$ injection in the Utsira Sand at Sleipner, offshore Norway. First Break, 26, 65 - 72. [2008]. 
3. Cavanagh, A.J., Haszeldine, R.S. and Blunt, M.J.. Open or closed? A discussion of the mistaken assumptions in the Economides analysis of carbon sequestration. Journal of Petroleum Science and Enginering, 74, 107-110. [2010].

4. Chadwick, R.A., Arts, R., Bernstone, C., May, F., Thibeau, S and Zweigel, P. Best Practice for the Storage of $\mathrm{CO}_{2}$ in Saline Aquifers. (Keyworth, Nottingham: British Geological Survey Occasional Publication No. 14. ISBN: 978-0-85272-610-5. 277 pp. [2008].

5. Ehlig-Economides, C.A. and Economides, M.J. Sequestering carbon dioxide in a closed underground volume. Journal of Petroleum Science and Enginering, 70, 123-130. [2010].

6. ZEP ZEP-CO2_Storage Capacity. http://www.zeroemissionsplatform.eu/ccstechnology/storage.html. [2010] 